\title{
Radiation Shielding Properties Prediction of Barite used as Small Aggregate in Mortar
}

\author{
Hoang Quoc $\mathrm{Vu}$ \\ Faculty of Civil Engineering \\ Ho Chi Minh City University of Technology (HCMUT) \\ Vietnam National University Ho Chi Minh City \\ Ho Chi Minh City, Vietnam \\ vqhoang@hcmut.edu.vn \\ Phong Thanh Nguyen \\ Department of Project Management \\ Faculty of Civil Engineering \\ Ho Chi Minh City Open University \\ Ho Chi Minh City, Vietnam \\ phong.nt@ou.edu.vn
}

\author{
Van Hoang Tran \\ Faculty of Civil Engineering \\ Ho Chi Minh City University of Technology (HCMUT) \\ Vietnam National University Ho Chi Minh City \\ Ho Chi Minh City, Vietnam \\ 1614062@hcmut.edu.vn \\ Nhi Thi Uyen Le \\ Faculty of Civil Engineering \\ Ho Chi Minh City University of Technology (HCMUT) \\ Vietnam National University Ho Chi Minh City \\ Ho Chi Minh City, Vietnam \\ 1612416@hcmut.edu.vn
}

\author{
Mai Thanh Le \\ Faculty of Civil Engineering \\ Ho Chi Minh City University of Technology (HCMUT) \\ Vietnam National University Ho Chi Minh City \\ Ho Chi Minh City, Vietnam \\ thanhmaia8@gmail.com
}

\begin{abstract}
Construction materials used in the nuclear industry used to be mainly heavy materials, including lead plates, radiationresistant heavy concrete, etc. However, these materials are either toxic after a long time of use (lead) or difficult to construct (radiation-resistant heavy concrete) and their cost is rather high. Therefore, there is a need for the manufacturing of a new kind of material with good radiation resistance, which is light, easy to use, and costs less. Barium is less toxic and more cost-effective than lead. Due to the importance of barium compounds in radiation shielding, the study of gamma radiation interactions within these compounds becomes essential, so the most important part of such a study is the experimental one, which shows the effect of the barite powder in the radiation resistance of the mortar. The research results show that the higher the thickness and percentage of barite powder, the higher is the radiation resistance.
\end{abstract}

Keywords-barite mortar; radiation protection material; compressive strength; volumetric mass; construction material; civil engineering

\section{INTRODUCTION}

Currently, nuclear technology is being widely applied in industry fields that divert from the narrow energy sector. The application of this technology in the manufacturing process provides a solution for coping with the challenges of global development (i.e. ensuring energy security, environment protection, food safety, etc.). Modern tendencies require creating better and safer lead-free materials $[1,2]$. Authors in [3] studied the influence of barite content in polymer composites, while the gadolinium oxide is presented as effective filler in [4]. Authors in [5] gave an example of using bismuth as filler for protection against gamma-rays.

In nature, the following types of radiation occur as the majority: Gamma (including X-rays), beta, and alpha radiation. Among these radiation types, gamma radiation is the most dangerous because of its high appearance probability and running distance. The running distance of alpha and beta radiation is shorter and their penetration is weaker, so any material that can block gamma radiation will also block alpha and beta. There is also the neutron-ray radiation that should be considered. An effective way to improve the resistance to neutron radiation is to increase the proportion of elements with low atomic mass. Theoretically, materials like serpentin that contain much bonding water (including wet materials) or use modified additives based on paraffin emulsions will resist neutron radiation more [6]. In fact, the source of neutron radiation is usually placed in a heavy concrete water tank, which will prevent neutron rays and is a cost-effective solution. The gamma radiation will interact primarily with the encapsulated electrons in the atomic shell. That interaction means being completely absorbed or losing energy, which will

Corresponding author: Hoang Quoc Vu and Phong Thanh Nguyen 
weaken or destroy the gamma radiation. Therefore, when choosing a shielding material, attention must be paid to the factor of high electron density (electron $/ \mathrm{cm}^{3}$ ), but for high electron density, the number of protons (the $\mathrm{Z}$ number) of the atoms should be large, and the density of the shielding material also should be greater $\left(\right.$ atoms $/ \mathrm{cm}^{3}$ ) [7]. Therefore, the metal element barium $(\mathrm{Ba})(\mathrm{Z}=56)$ in the barium sulfate compound $\mathrm{BaSO}_{4}$ is suitable for radiation shielding, because it is chemically stable, easy to preserve, pack, and transport, less affected by the surrounding environment, easy to produce, has low cost, it is safe, and easy to use [8,9].

However, blocking gamma and $\mathrm{X}$ rays completely is very difficult, almost impossible, because they can penetrate materials in large depths. However, we can still control the amount of these radiations when released into the environment within the permissible limit of not affecting human health. Globally, fabrication and mortar experience show that the adhesives that make the mortar resistant are Portland cement and Portland cement blends. After hydration and curing, the cement will withhold a quantity of bonding water. This has a significant effect on the grout's ability to resist neutrons. If we add a mineral powder with a high molecular weight, it will increase the mortar's ability to resist gamma and $\mathrm{X}$ rays.

\section{RESEARCH BACKGROUND}

Materials for manufacturing barite mortar include [10]:

- Cement: PCB40 cement and construction sand are commonly used. Yellow sand is carefully screened.

- High content of barite powder: The main ingredient of barite powder is $\mathrm{BaSO}_{4}$, an inorganic compound with massive molecular weight, thus an effective anti-radiation material [11].

- Clean water: Well water or tap water can be used.

Barite mortar is a particular type of mortar used to prevent radiation. Therefore, when conducting experiments to check the technical properties of barite mortar, it is unnecessary to apply all the provisions of TCVN 4314-2003 for ordinary mortar. We conducted experiments examining the physical properties of the 11 calculated gradients shown in Table I. Depending on each experiment, the properties of some gradients or the whole material will be tested. The experiments' focus is the graded design for barite mortar equivalent to standard mortar, investigating barite mortar's resistivity.

\section{RESULTS AND DISCUSSION}

\section{A. Determing the Consistency of Fresh Mortar}

Before testing, the surface of the glass, cone, and pestle was wiped with a damp cloth. A cone-shaped stitch was placed in the middle of the ballast table. Eleven pre-mixed fresh mortar samples were poured in two layers, each layer with compaction of about ten pieces so that the mortar was full and homogeneous in the stitch. When compacting, the stitch was helped on the flow table by hand, as shown in Figure 1. The excess mortar on the surface was flattened with a trowel, the water and mortar on the surrounding glass were wiped off, the stitch was slowly lift up vertically and the ballast was left 15 times for $15 \mathrm{~s}$. The diameter of the bottom of the mortar mass was measured in two perpendicular directions to the nearest $\mathrm{mm}$. The test result was the average of the two measurements. The consistency of the mortar sample is the average result of the two tests. If one of the two measurement errors was greater than $10 \%$ of the average value, the experiment was repeated (Figure 2).

TABLE I. THE AGGREGATES OF 11 TEST SAMPLES

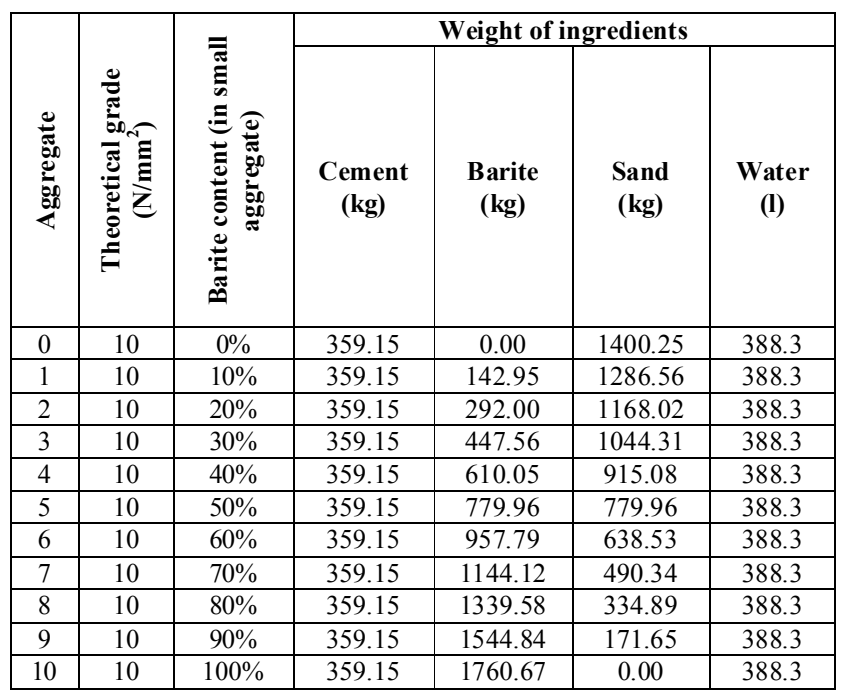
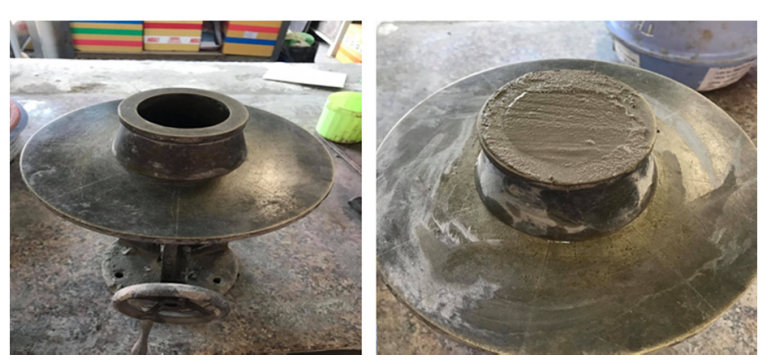

Fig. 1. The fresh mortar into the cone shape of the flow table.

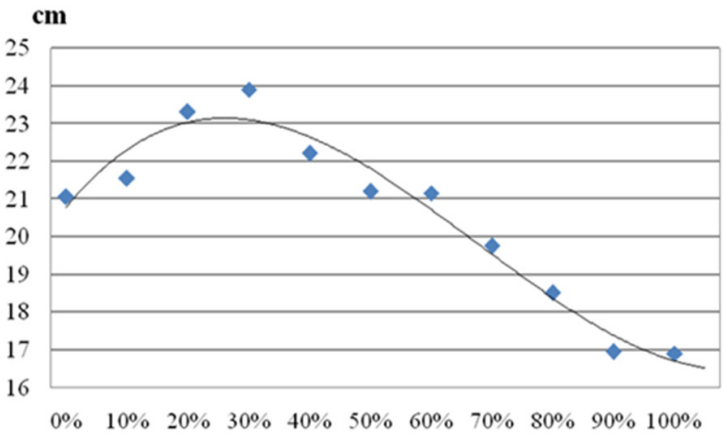

Barite content $(\%)$

Fig. 2. The consistency of the mortar.

The main findings were:

- When adding 10-30\% barite powder, the small surface area leads to a decrease of the amount of water required to wet the surface and the amount of cement slurry required to 
lubricate the aggregate surface also decreases, but the amount of water and cement remained unchanged resulting in increased fluidity.

- The total surface area of barite powder is greater than the total surface area of sand, but the amount of cement remains the same, so the quantity of cement paste is not enough to cover all fine aggregate particles (mainly barite powder). This makes the particles easier to contact, increasing the dry friction, resulting in reduced fluidity of the mortar mixture. For barite ratio of $30 \%$, the mortar achieves the highest fluidity.

\section{B. Determining the Setting Time of the Fresh Mortar}

The utilized tools were a clock, technical scales to an accuracy of $0.1 \mathrm{~g}$, and Vikat tools. The results are shown in Figure 3. It was shown that the setting time of the mortar sample decreases when the concentration of barite in the aggregate increases. According to the theoretical scientific basis, barite powder is an inert compound with normal chemical behavior, which means that barite is almost impossible to participate in a chemical reaction with cement, sand, and water during the closing process. Thus, adding barite to the mortar will not significantly change its setting time. However, according to Figure 3, as the barite content increases, the setting time of the mortar decreases. This can only be explained because the higher the barite content of the mortar mixture, the more pliability, adhesion, and high frictional force with the Vikat needle increase, this hinders the Vikat needle settlement and leads to incorrect setting time. In addition, because the barite grain is smaller than the sand, the contact between cement and water is not limited, so the setting time is shortened.

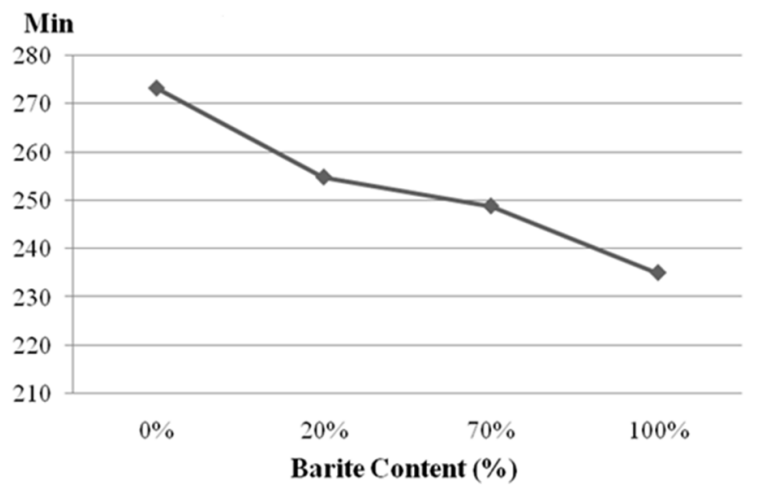

Fig. 3. Setting time of the mortar vs the barite content.

\section{Flexural and Compressive Strength of the Hardened Mortar}

For sample preparation, it took approximately $2 \mathrm{~L}$ of a prepared mortar sample. The mortar was cast in molds with a metal base. The mold was covered with a thin layer of mineral oil. The mortar was poured into the mold in two layers, using pestle to compact each layer. The molded mortar sample was cured for 1 day in the mold (sealed at room temperature) and, after the mold removal, for 27 days in water (Figures 4-5). Experiments with flexural and compressive strength of the mortar were conducted according to [12] (Figure 6).

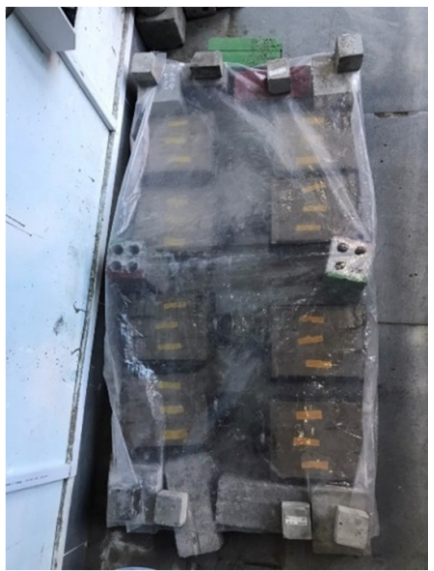

Fig. 4. The samples were cured for one day in the mold.

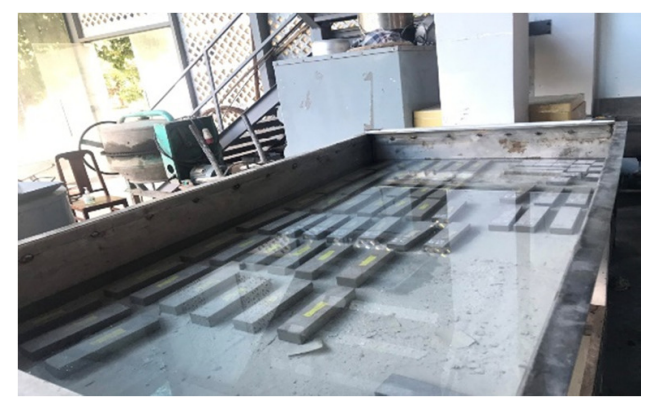

Fig. 5. The samples were cured for 27 days in water.

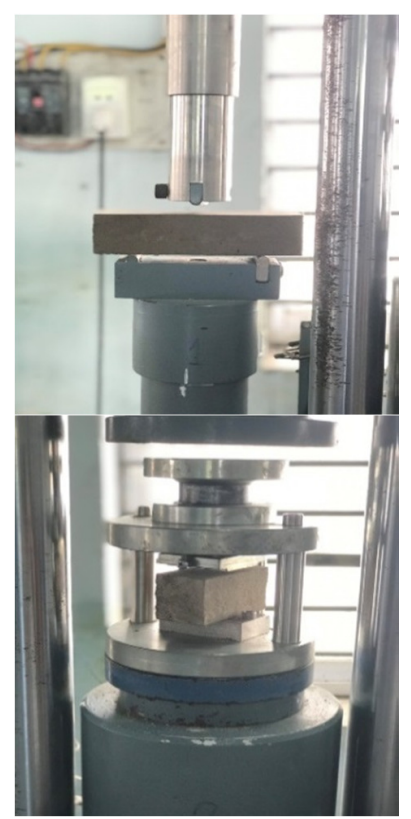

Fig. 6. Bending test. (a) Compressing sample, (b) barite mortar.

The experimental results are shown in Tables II and III. The strength of barite mortar increases over time as the percentage content of barite in the aggregate increases, the bending and compressive strength of the mortar samples decreases and becomes lower than the theoretically calculated strength of the mortar because barite powder has a higher fineness and smaller 
magnitude module than sand, so the total surface area of barite powder will be larger than sand's.

TABLE II. BENDING TEST RESULTS

\begin{tabular}{|c|c|c|c|c|c|}
\hline \multirow{2}{*}{$\#$} & \multirow{2}{*}{$\begin{array}{c}\text { Theoretical } \\
\text { grade }\end{array}$} & \multirow{2}{*}{$\begin{array}{c}\text { Barite content } \\
\text { (in small }\end{array}$} & \multicolumn{3}{|c|}{$\begin{array}{c}\text { Flexural strength } \mathbf{R}_{\mathbf{u}} \\
\left(\mathbf{N} / \mathbf{m m}^{\mathbf{2}} \mathbf{)}\right.\end{array}$} \\
\cline { 4 - 6 } & $\left.\mathbf{N} / \mathbf{m m}^{2}\right)$ & aggregates) & 3 days & $\mathbf{7}$ days & 28 days \\
\hline 0 & 10 & $0 \%$ & 2.67 & 2.91 & 3.77 \\
\hline 1 & 10 & $10 \%$ & 2.54 & 2.86 & 3.68 \\
\hline 2 & 10 & $20 \%$ & 2.52 & 2.69 & 3.49 \\
\hline 3 & 10 & $30 \%$ & 2.34 & 2.55 & 3.45 \\
\hline 4 & 10 & $40 \%$ & 2.23 & 2.53 & 3.33 \\
\hline 5 & 10 & $50 \%$ & 2.22 & 2.52 & 3.30 \\
\hline 6 & 10 & $60 \%$ & 2.17 & 2.45 & 3.12 \\
\hline 7 & 10 & $70 \%$ & 2.15 & 2.42 & 2.95 \\
\hline 8 & 10 & $80 \%$ & 2.14 & 2.28 & 2.88 \\
\hline 9 & 10 & $90 \%$ & 1.88 & 2.01 & 2.64 \\
\hline 10 & 10 & $100 \%$ & 1.71 & 1.85 & 2.47 \\
\hline
\end{tabular}

TABLE III. COMPRESSION TEST RESULTS

\begin{tabular}{|c|c|c|c|c|c|}
\hline \multirow[t]{2}{*}{$\#$} & \multirow{2}{*}{$\begin{array}{c}\text { Theoretical } \\
\text { grade } \\
\left(\mathbf{N} / \mathbf{m m}^{2}\right)\end{array}$} & \multirow{2}{*}{$\begin{array}{c}\text { Barite content } \\
\text { (in small } \\
\text { aggregates) }\end{array}$} & \multicolumn{3}{|c|}{$\begin{array}{c}\text { Compressive strength } R_{n} \\
\left(\mathrm{~N} / \mathrm{mm}^{2}\right)\end{array}$} \\
\hline & & & 3 days & 7 days & 28 days \\
\hline 0 & 10 & $0 \%$ & 6.73 & 8.29 & 11.63 \\
\hline 1 & 10 & $10 \%$ & 6.59 & 8.03 & 10.98 \\
\hline 2 & 10 & $20 \%$ & 6.37 & 7.79 & 10.79 \\
\hline 3 & 10 & $30 \%$ & 6.33 & 7.56 & 10.61 \\
\hline 4 & 10 & $40 \%$ & 6.22 & 7.23 & 10.24 \\
\hline 5 & 10 & $50 \%$ & 5.59 & 6.29 & 10.16 \\
\hline 6 & 10 & $60 \%$ & 5.48 & 6.20 & 9.84 \\
\hline 7 & 10 & $70 \%$ & 4.67 & 6.14 & 9.80 \\
\hline 8 & 10 & $80 \%$ & 4.66 & 6.05 & 9.62 \\
\hline 9 & 10 & $90 \%$ & 4.62 & 5.98 & 9.35 \\
\hline 10 & 10 & $100 \%$ & 4.43 & 5.71 & 9.16 \\
\hline
\end{tabular}

It takes more cement than the theoretical calculated cement to cover all fine barite particles. Insufficient cement will cause poor bonding in the mortar structure resulting in reduced strength. The mixture of barite mortar has low mobility, it is challenging to mix, leading to irregular mixing, so many pores appear, reducing the barite mortar strength.

\section{The Volume of Solid Mortar Samples}

Solidified mortar tablets which have been cast in $40 \mathrm{~mm} \times 40 \mathrm{~mm} \times 160 \mathrm{~mm}$ molds were used. The mortar was cured under specified conditions, for not less than 28 days. The samples were dried at $1050^{\circ} \mathrm{C}+50^{\circ} \mathrm{C}$, were cooled to room temperature, and weighed. Three measurements were taken, the result of each edge is the average of the three measurements at 3 different locations.

$$
\mathrm{P}=\frac{\mathrm{m}_{1}}{1 . b \cdot h}
$$

where $P$ is the mass of test pieces $\left(\mathrm{kg} / \mathrm{m}^{3}\right), \mathrm{m}_{1}$ is the mass of the sample in dry state $(\mathrm{kg})$ and $\mathrm{l}, \mathrm{b}, \mathrm{h}$ are the length, width, and height of the test piece $(\mathrm{m})$. The test result is the average of the results of the two test pieces shown in Figure 7. The more the barite content, the more the volume of solid mortar sample increases.

\section{E. The Resistivity of Solid Mortar Samples}

The following equation shows the resistivity of the antiradioactive material:

$$
\mathrm{I}=\mathrm{I}_{0} \times \mathrm{e}^{-\sum \mathrm{d}}
$$

where $I$ is the radiation intensity after passing through the material, $\mathrm{I}_{0}$ is the radiation intensity without material thickness, $\mathrm{d}$ is the thickness of the material layer $(\mathrm{cm}), \Sigma$ is the material's linear absorbance coefficient (also known as the linear attenuation coefficient of the radiation) $\left(\mathrm{cm}^{-1}\right)$. It is equal to the mass absorption coefficient times the density of the material [13].

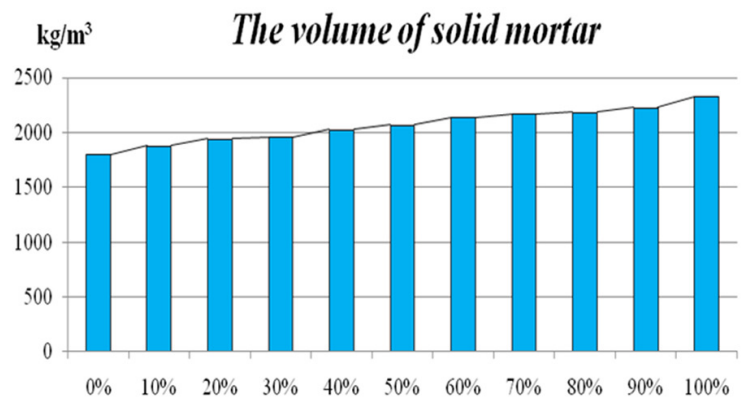

Barite content in small aggregate $(\%)$

Fig. 7. The volume of solid mortar sample vs the barite content

The mass absorption coefficient depends on the energy level of the radioactive source. The smaller the I, the smaller the ratio $\mathrm{I} / \mathrm{I}_{\mathrm{o}}$ and the better radiation resistant is the material. On the other hand, as the thickness $d$ increases, the ratio $I / I_{0}$ also decreases, leading to smaller I which means better radiation resistant material. After 28 days of water curing, the mortar samples were cut into pieces with different thicknesses $(2 \mathrm{~cm}$, $3 \mathrm{~cm}, 4 \mathrm{~cm}$ and $5 \mathrm{~cm}$ ). These thicknesses need to be checked in order to investigate the radioactive resistance of barite mortar. The pieces were shot by radiation rays in the laboratory. The change in resistance was investigated considering two factors: the thickness of the mortar and the barite content. A total of 88 samples were sent to the Ho Chi Minh City Nuclear Center laboratory. A collimator with an internal diameter of $2.5 \mathrm{~cm}$ was used to orient the radiation, to create an accurate correlation between the gamma-ray position and the direction of that gamma-ray when interacting with the mortar sample. The collimator also helped limit the unnecessary radiation outside the study area (background radiation) and can be seen in Figure 8.

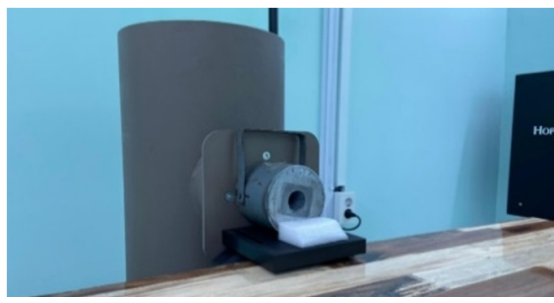

Fig. 8. Collimator.

The mortar samples were placed on a support, in such a way that the radiation could penetrate them (Figure 9). The testing time for each mortar sample was $15 \mathrm{~min}$. At first, the 
dose rate results when there was no sample were measured, then the sample was placed in the measuring position and the dose rate was measured. The obtained results were recorded on a detector in $\mu \mathrm{Sv} / \mathrm{h}$ (Figures10 and 11). Each sample was measured 10 times and the results were averaged.

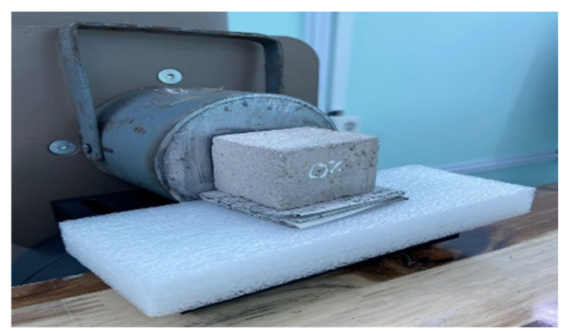

Fig. 9. The posotion of the test mortar sample.

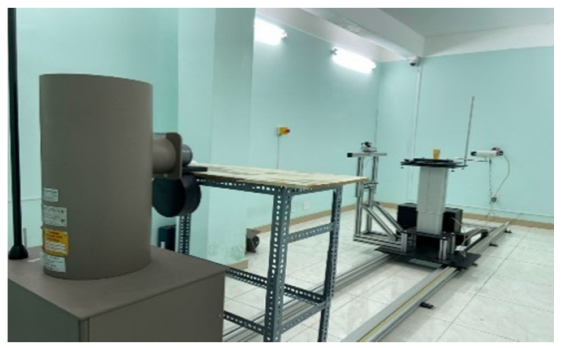

Fig. 10. Equipment layout position.

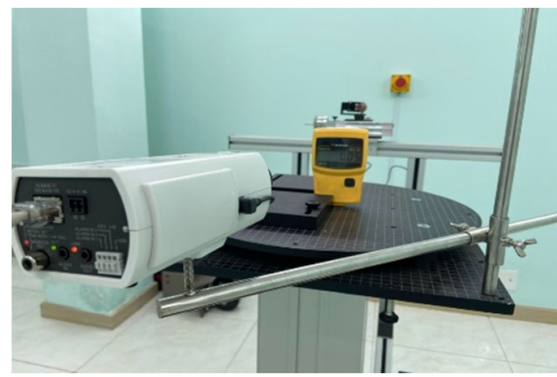

Fig. 11. Detector.

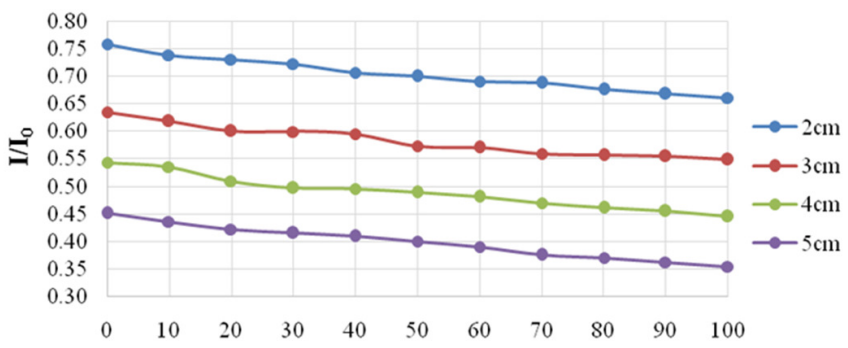

The Barite content in small aggregate $(\%)$

Fig. 12. Radiation attenuation for various mortar thickness and barite content percentage values.

The ratio $\mathrm{I} / \mathrm{I}_{0}$ of the experimental results and $\mathrm{XCOM}$ is compared in Figures $13-16$. From the ratio $\mathrm{I} / \mathrm{I}_{0}$, the linear attenuation coefficient is computed and the experimental results with XCOM can be compared as shown in Table IV and Figure 17.

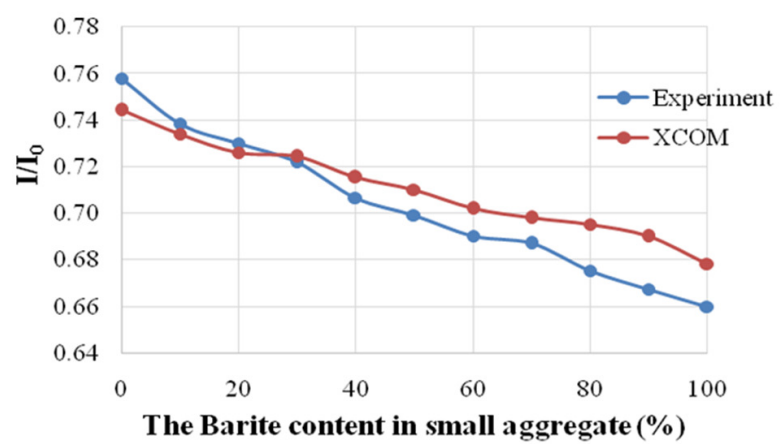

Fig. 13. Radiation attenuation of $2 \mathrm{~cm}$ barite mortar.

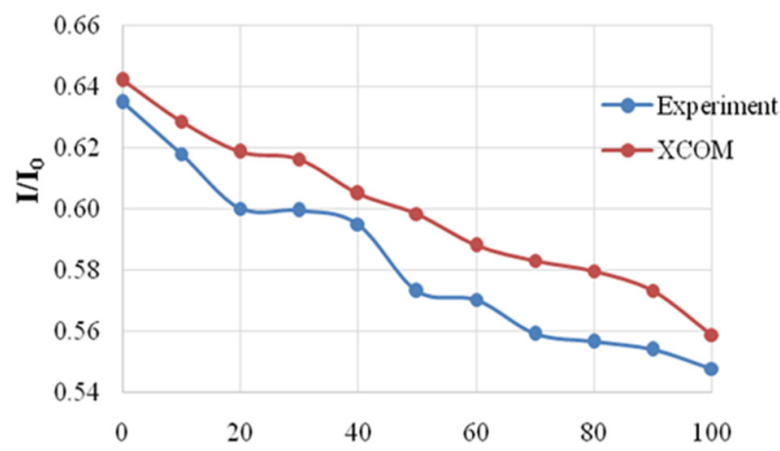

The Barite content in small aggregate $(\%)$

Fig. 14. Radiation attenuation of $3 \mathrm{~cm}$ barite mortar.

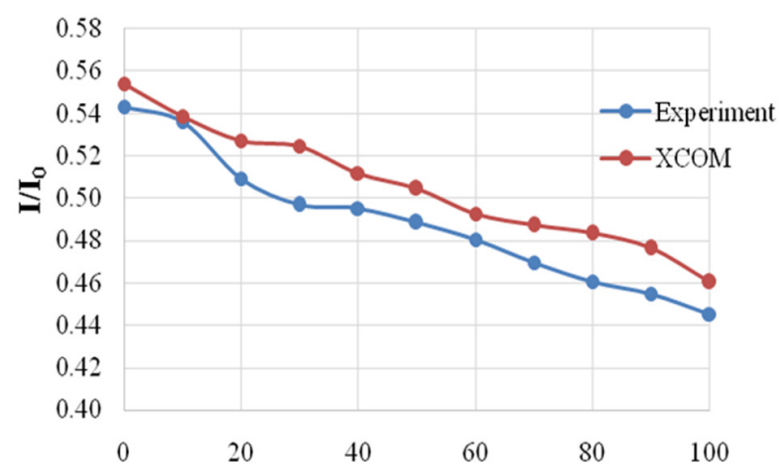

The Barite content in small aggregate $(\%)$

Fig. 15. Radiation attenuation of $4 \mathrm{~cm}$ barite mortar.

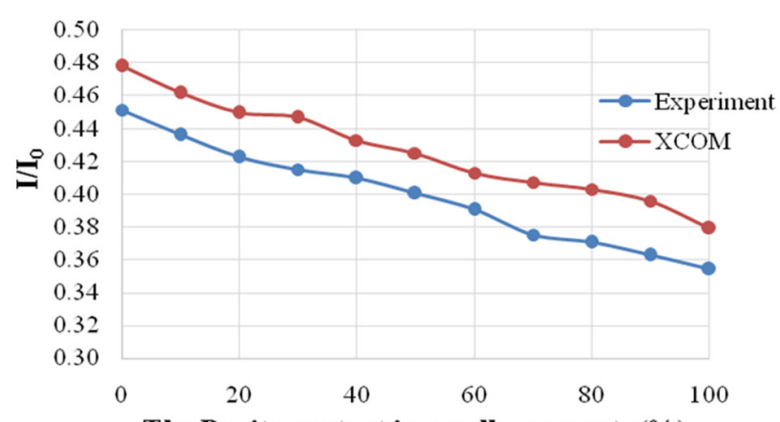

The Barite content in small aggregate (\%)

Fig. 16. Radiation attenuation of $5 \mathrm{~cm}$ barite mortar. 
TABLE IV. XCOM AND EXPERIMENTAL LINEAR ATTENUATION COEFFICIENT

\begin{tabular}{|c|c|c|c|}
\hline$\#$ & $\begin{array}{c}\text { Sum of XCOM } \\
\left(\mathbf{c m}^{-\mathbf{1}}\right)\end{array}$ & $\begin{array}{c}\text { Sum of experiment } \\
\left(\mathbf{c m}^{-\mathbf{1}}\right)\end{array}$ & $\boldsymbol{\Delta} \mathbf{( \% )}$ \\
\hline 0 & 0.1477 & 0.1514 & 2.52 \\
\hline 1 & 0.1546 & 0.1585 & 2.50 \\
\hline 2 & 0.1600 & 0.1671 & 4.44 \\
\hline 3 & 0.1613 & 0.1711 & 6.12 \\
\hline 4 & 0.1675 & 0.1752 & 4.60 \\
\hline 5 & 0.1711 & 0.1816 & 6.16 \\
\hline 6 & 0.1769 & 0.1860 & 5.10 \\
\hline 7 & 0.1798 & 0.1916 & 6.55 \\
\hline 8 & 0.1817 & 0.1960 & 7.85 \\
\hline 9 & 0.1854 & 0.1997 & 7.68 \\
\hline 10 & 0.1939 & 0.2045 & 5.47 \\
\hline
\end{tabular}
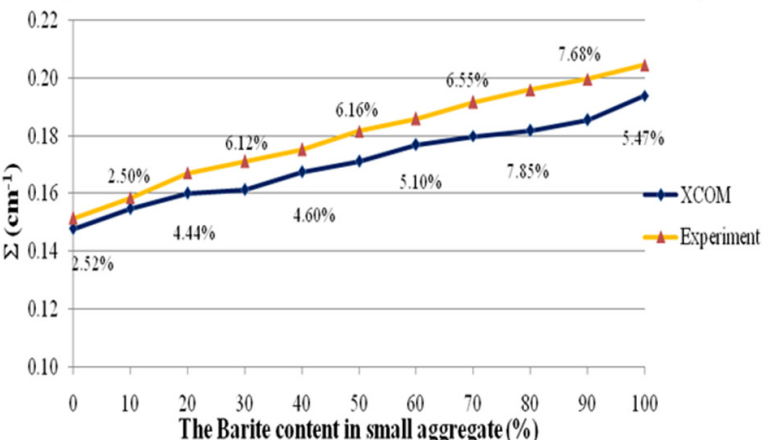

Fig. 17. Linear attenuation coefficient: Comparison of the experimental results with XCOM

Both experiment and XCOM results showed that as the thickness increases, the radiation resistance of the mortar increases, and as the barite content increases, the linear attenuation coefficient increases along with the radiation resistance of the mortar. The difference between the XCOM and the experimental results is within the acceptable limits. The results of this experiment are in accordance with the ones in $[14,15]$. The current research calculated the corresponding energy levels and the obtained result is shown in Figure 18. For the high energy level $(662 \mathrm{keV})$, the radiation resistance will be more effective when increasing the mortar sample thickness. Corresponding to the low energy level $(150 \mathrm{keV})$, when increasing the concentration of barite in the aggregate, the radiation resistance will be more effective.

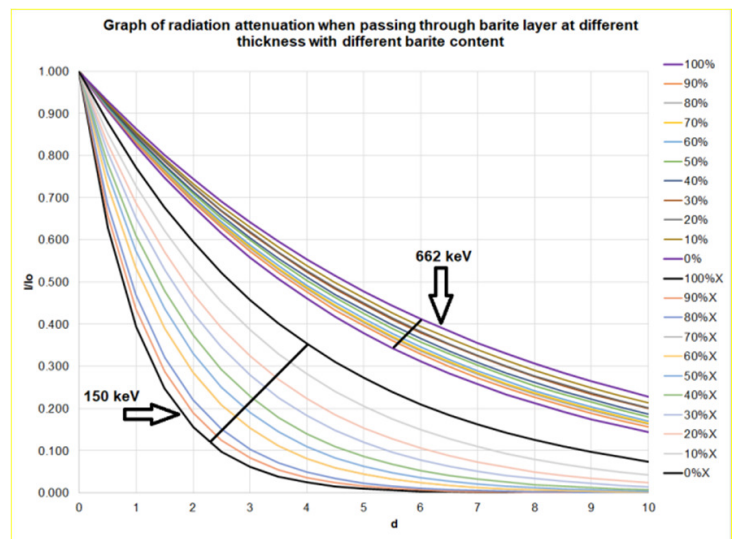

Fig. 18. Radiation attenuation when passing through barite layers of varying thickness and barite content.

\section{CONCLUSION}

The Vietnamese economy shows growth overcoming obstacles and challenges [16-18]. This is partially due to the research successes of the construction and engineering material segments [19-22]. This paper showed that barite mortar's consistency is higher than standard mortar's when sand is replaced with barite powder in percentages up to $30 \%$. For replacement ratio above $30 \%$ a decrease in fluidity is noticed. Therefore, when making barite mortar, it is necessary to increase the amount of mixing water and the corresponding amount of cement. When increasing the barite content in the mortar sample, the setting time of the mortar is shortened, but not significantly. The barite mortar sample's flexural and compressive strength decrease gradually as the barite content increases. This can be entirely overcome by increasing the amount of cement while increasing the corresponding amount of water when mixing. In addition, mechanical mixing helps to mix evenly and achieve high uniformity, which also improves the mortar's strength. When designing, a 100-grade mortar mix was chosen, but in fact, the purpose of using barite mortar is only to improve its radiation resistance. Therefore, although the mortar's compressive strength after 28 days is lower than $10 \mathrm{~N} / \mathrm{mm}^{2}$ (design), it is completely applicable.

\section{ACKNOWLEDGMENT}

This research is fund by the Vietnam National University, Ho Chi Minh City (VNU-HCM) under the grant number B2018-20-05. We acknowledge the support and the facility provision of the Ho Chi Minh City University of Technology (HCMUT) and VNU-HCM.

\section{REFERENCES}

[1] S. Nambiar and J. T. W. Yeow, "Polymer-Composite Materials for Radiation Protection," ACS Applied Materials \& Interfaces, vol. 4, no. 11, pp. 5717-5726, Sep. 2012.

[2] W. Poltabtim, E. Wimolmala, and K. Saenboonruang, "Properties of lead-free gamma-ray shielding materials from metal oxide/EPDM rubber composites," Radiation Physics and Chemistry, vol. 153, pp. 1-9, Dec. 2018, https://doi.org/10.1016/j.radphyschem.2018.08.036.

[3] N. I. Cherkashina, V. I. Pavlenko, and A. V. Noskov, "Radiation shielding properties of polyimide composite materials," Radiation Physics and Chemistry, vol. 159, pp. 111-117, Jun. 2019, https://doi.org/10.1016/j.radphyschem.2019.02.041.

[4] R. Li, Y. Gu, Y. Wang, Z. Yang, M. Li, and Z. Zhang, "Effect of particle size on gamma radiation shielding property of gadolinium oxide dispersed epoxy resin matrix composite," Materials Research Express, vol. 4, no. 3, Mar. 2017, Art. no. 035035, https://doi.org/ 10.1088/2053-1591/aa6651.

[5] S. Y. Yashkina, V. A. Doroganov, Y. N. Trepalina, V. A. Loktionov, and E. I. Evtushenko, "Matrices of radiation-protective composites using bismuth oxide," IOP Conference Series: Materials Science and Engineering, vol. 327, Mar. 2018, Art. no. 032061, https://doi.org/ 10.1088/1757-899X/327/3/032061.

[6] J. Yang, Z. F. Chen, Y. C. Gan, and Q. W. Tao, "Research Progress on Radiation Shielding Concrete," Applied Mechanics and Materials, vol. 253-255, pp. 303-307, 2013, https://doi.org/10.4028/www. scientific.net/AMM.253-255.303.

[7] T. Piotrowski, D. B. Tefelski, M. Mazgaj, J. Skubalski, A. Żak, and J. J. Sokołowska, "Polymers in Concrete - The Shielding against Neutron Radiation," Advanced Materials Research, vol. 1129, pp. 131-138, 2015, https://doi.org/10.4028/www.scientific.net/AMR.1129.131.

[8] M. T. Lakhiar, N. Mohamad, A. A. Jhatial, S. Sohu, and M. Oad, "Mechanical Properties of Concrete Containing River Indus Sand and 
Recyclable Concrete Aggregate," Civil Engineering Journal, vol. 4, no. 8, pp. 1869-1876-1876, Aug. 2018, https://doi.org/10.28991/cej03091121 .

[9] A. N. Grishina, E. V. Korolev, and A. B. Satyukov, "RadiationProtective Composite Binder Extended with Barium Hydrosilicates," Advanced Materials Research, vol. 1040, pp. 351-355, 2014, https://doi.org/10.4028/www.scientific.net/AMR.1040.351.

[10] W. G. Wu et al., "Construction and Quality Control of Concrete Using Barite as Aggregate," Key Engineering Materials, vol. 302-303, pp. 462-469, 2006, https://doi.org/10.4028/www.scientific.net/KEM.302303.462 .

[11] T. Huang, S. M. Lei, E. W. Wang, and G. M. Bao, "Progress of Purification and Application of Barite," Applied Mechanics and Materials, vol. 423-426, pp. 511-514, 2013, https://doi.org/10.4028/ www.scientific.net/AMM.423-426.511.

[12] Mortar for masonry - Test methods, TCVN 3121:2003. 2003.

[13] V. Harish, N. Nagaiah, T. N. Prabhu, and K. T. Varughese, "Preparation and characterization of lead monoxide filled unsaturated polyester based polymer composites for gamma radiation shielding applications," Journal of Applied Polymer Science, vol. 112, no. 3, pp. 1503-1508, 2009, https://doi.org/10.1002/app.29633.

[14] T. A. Almeida Junior, M. S. Nogueira, V. Vivolo, M. P. A. Potiens, and L. L. Campos, "Mass attenuation coefficients of X-rays in different barite concrete used in radiation protection as shielding against ionizing radiation," Radiation Physics and Chemistry, vol. 140, pp. 349-354, Nov. 2017, doi: 10.1016/j.radphyschem.2017.02.054.

[15] V. Cherkasov, V. Avdonin, Y. Yurkin, and D. Suntsov, "Prediction of radiation shielding properties of self adhesive elastic coating," Materials physics and mechanics, vol. 73, no. 6, pp. 825-836, 2019, https://doi.org/10.18720/MPM.4262019_14.

[16] M. T. H. Duong, D. V. Nguyen, and P. T. Nguyen, "Using Fuzzy Approach to Model Skill Shortage in Vietnam's Labor Market in the Context of Industry 4.0," Engineering, Technology \& Applied Science Research, vol. 10, no. 3, pp. 5864-5868, Jun. 2020, https://doi.org/ 10.48084/etasr.3596.

[17] P. T. Nguyen and P. C. Nguyen, "Risk Management in Engineering and Construction: A Case Study in Design-Build Projects in Vietnam," Engineering, Technology \& Applied Science Research, vol. 10, no. 1, pp. 5237-5241, Feb. 2020, https://doi.org/10.48084/etasr.3286.

[18] N. M. Ha and B. H. Ngoc, "Revisiting the relationship between energy consumption and economic growth nexus in Vietnam: new evidence by asymmetric ARDL cointegration," Applied Economics Letters, Jul. 2020, https://doi.org/10.1080/13504851.2020.1789543.

[19] K. D. Vo, P. T. Nguyen, and L. Le-Hoai, "The difference in personality traits of construction engineers in Vietnam using the KTS instrument," Suranaree Journal of Science and Technology, vol. 26, no. 2, pp. 236239, Apr. 2019.

[20] P. T. Nguyen, V. Likhitruangsilp, and M. Onishi, "Success Factors for Public-Private Partnership Infrastructure Projects in Vietnam," International Journal on Advanced Science, Engineering and Information Technology, vol. 10, no. 2, pp. 858-865, Mar. 2020, doi: 10.18517/ijaseit. 10.2.5839.

[21] N. T. Phong, "Application of supply chain management in construction industry," Advances in Science and Technology. Research Journal, vol. 12, no. 2, pp. 11-19, Jun. 2018, https://doi.org/10.12913/ $22998624 / 92112$.

[22] N. T. Phong, V. Likhitruangsilp, and M. Onishi, "Developing a stochastic traffic volume prediction model for public-private partnership projects," AIP Conference Proceedings, vol. 1903, no. 1, Nov. 2017, Art. no. 060010, https://doi.org/10.1063/1.5011564. 